\title{
Orthodontic Treatment and the Compromised Periodontal Patient
}

Young patients referred for orthodontic treatment often suffer from plaque related gingivitis. Many dentists are reluctant to refer adult patients for orthodontic treatment if they have suffered, or are suffering from, obvious signs of periodontal disease such as chronic periodontitis. Most humans suffer from periodontal disease at some time in their lives. The severity of the disease varies widely. Nearly all fixed orthodontic appliance patients will get gingivitis at some point during their treatment. ${ }^{1}$ Gingival enlargement and inflammation are often transient and resolves within weeks of debond. ${ }^{2}$ It has been suggested that the contemporary use of bonded rather than banded orthodontic appliances bonds may result in less gingivitis. ${ }^{3}$ Fixed orthodontic appliances cause an increase in all bacterial counts ${ }^{4}$ around the bracket and band's ecosystem. ${ }^{5}$ There is a decrease in facultative anaerobes and an increase in anaerobic rods, spirochaetes and other motile organisms. Adolescents have certainly been shown to suffer worse gingivitis than adults during orthodontic treatment. ${ }^{1}$ Interceptive treatment such as the correction of lower incisors in crossbite has been found to improve periodontal health. ${ }^{6}$ Orthodontically induced gingivitis especially the young, seems to be of little consequence in that it will resolve after orthodontic treatment in the healthy plaque free mouth.

There are however long-term effects seen in some patients. When loss of attachment in orthodontic patients compared with controls was examined, the data showed that $10 \%$ had significant attachment loss, but $50 \%$ had no attachment loss. ${ }^{7}$ A mean loss of gingival attachment of 0.1 mm occurred compared with controls and $10 \%$ of patients show significantly more destruction than average. Greater than 1-2 mm loss of alveolar bone has been reported ${ }^{8}$ during orthodontic treatment, but the any loss of attachment in orthodontic patients with good oral hygiene is very small reportedly as $0.2-0.3 \mathrm{~mm}$ compared with $0.1 \mathrm{~mm}$ in controls. ${ }^{9}$ Extraction sites have shown slightly greater bone loss. ${ }^{10}$ It seems however that progression to frank periodontal disease as a result of orthodontic treatment is uncommon. ${ }^{11}$ Orthodontic treatment has been suggested as having a lasting effect on oral hygiene as patients maybe more aware of dental health. Long term studies however, report no difference in periodontal status between post-orthodontic and non-orthodontic patients. ${ }^{12}$

Adult periodontally compromised patients often present with drifting teeth leading to the development, or worsening, of a malocclusion. Many orthodontists are often reluctant to provide fixed appliance therapy. There is good evidence that provided high quality periodontal intervention is carried out and the patient is able to maintain adequate hygiene procedures to control the disease, even in the presence of previous alveolar bone loss, then fixed appliance treatment can be carried out safely and satisfactorily. The primary aim before orthodontic intervention is to stabilise the periodontal condition. ${ }^{13}$ The possible orthodontic tooth movements include alignment, space redistribution and intrusion. . $^{14,15}$ Bone loss alters the position of the centre of resistance to teeth and force required to achieve movement but the orthodontist can use reduced or increased force moments as indicated to avoid excessive alveolar bone loss. The use of tipping appliances such as the "Tip Edge" appliance will move the crown quickly without apical root movement, which may be wise in cases with horizontal bone loss. Permanent retention in such cases is always necessary by fixed or removable retainers and long-term maintenance and regular screening is mandatory in such adult cases. 
Clinical experience of the orthodontic treatment of patients who have been successful in controlled their chronic periodontal disease is now good and such patients should not be denied orthodontic treatment.

\section{REFERENCES}

1. Boyd RL, Baumrind S. Periodontal implications of orthodontic treatment in adults with reduced or normal periodontal tissue versus those of adolescents. Angle Orthod 1992;62:117-126.

2. Zachrisson S, Zachrisson BU. Gingival condition associated with orthodontic treatment. Angle Orthod 1972;42:26-34.

3. Alexander SA. Effects of orthodontic attachments on the gingival health of permanent $2^{\text {nd }}$ molars. Am J Orthod Dentofac Orthop 1991;199:337-340.

4. Bloom RH, Brown LR. A study of the effects of orthodontic appliances on oral microbiological flora. Oral Surg Oral Med Oral Path 1964;17:658-667.

5. Diamanti-Kipioti A, Gusberti FA, Lang NP. Clinical and microbiological effects of fixed orthodontic appliances. $J$ Clin Periodontol 1987;14:326-333.

6. Eismann D, Prusas R. Periodontal findings before and after orthodontic therapy in cases of lower incisor cross-bite. Eur J Orthod 1990;12:281-283.

7. Zachrisson BU. Cause and prevention of injuries to teeth and supporting structures during orthodontic treatment. Am J Orthod 1976;69:285-300.

8. Alstad S, Zachrisson BU. Longitudinal study of periodontal condition associated with orthodontic treatment in adolescents. Am J Orthod 1979;76:277-286.

9. Hamp SE, Johansson LA. Dental prophylaxis for youths in their late teens. I. Clinical effect of different preventive regimes on oral hygiene, gingivitis and dental caries. J Clin Periodontol 1982;9:22-34.

10. Zachrisson BU, Alnaes L. Periodontal condition in orthodontically treated and untreated individuals. II. Alveolar bone loss: radiographic findings. Angle Orthod 1974;44:48-55.

11. Sadowsky C, BeGole EA. Long-term effects of orthodontic treatment on periodontal health. Am J Orthod 1981;80:156172.

12. Polson AM, Subtelny JD, Meitner SW, Polson AP, Sommers EW, Iker HP, Reed BE. Long term periodontal status after orthodontic treatment. Am J Orthod Dentofac Orthop 1988;93:51-58.

13. Boyd RL, Murray P, Robertson PB. Effect of rotary toothbrush versus manual toothbrush on periodontal status during orthodontic treatment. Am J Orthod Dentofac Orthop 1989;96:342-347.
14. Eliasson LA, Hugoson A, Kurol J, Siwe H. The effects of orthodontic treatment on periodontal tissues in patients with reduced periodontal support. Eur J Orthod 1982;4:1-9.

15. Steffensen B, Storey AT. Orthodontic intrusive forces in the treatment of periodontally compromised incisors: a case report. Int J Perio Rest Dent 1993;13:433-441. 